\title{
Application of simple fed-batch technique to high-level secretory production of insulin precursor using Pichia pastoris with subsequent purification and conversion to human insulin
}

\author{
Chandrasekhar Gurramkonda1,2, Sulena Polez³, Natasa Skoko33, Ahmad Adnan1,4, Thomas Gäbel1,5, Dipti Chugh², \\ Sathyamangalam Swaminathan², Navin Khanna22, Sergio Tisminetzky³ and Ursula Rinas*1
}

\begin{abstract}
Background: The prevalence of diabetes is predicted to rise significantly in the coming decades. A recent analysis projects that by the year 2030 there will be $\sim 366$ million diabetics around the world, leading to an increased demand for inexpensive insulin to make this life-saving drug also affordable for resource poor countries.

Results: A synthetic insulin precursor (IP)-encoding gene, codon-optimized for expression in P. pastoris, was cloned in frame with the Saccharomyces cerevisiae a-factor secretory signal and integrated into the genome of P. pastoris strain X33. The strain was grown to high-cell density in a batch procedure using a defined medium with low salt and high glycerol concentrations. Following batch growth, production of IP was carried out at methanol concentrations of $2 \mathrm{~g} \mathrm{~L}^{-}$ 1, which were kept constant throughout the remaining production phase. This robust feeding strategy led to the secretion of $\sim 3$ gram IP per liter of culture broth (corresponding to almost 4 gram IP per liter of cell-free culture supernatant). Using immobilized metal ion affinity chromatography (IMAC) as a novel approach for IP purification, 95\% of the secreted product was recovered with a purity of $96 \%$ from the clarified culture supernatant. Finally, the purified IP was trypsin digested, transpeptidated, deprotected and further purified leading to $\sim 1.5 \mathrm{~g}$ of $99 \%$ pure recombinant human insulin per liter of culture broth.

Conclusions: A simple two-phase cultivation process composed of a glycerol batch and a constant methanol fedbatch phase recently developed for the intracellular production of the Hepatitis B surface antigen was adapted to secretory IP production. Compared to the highest previously reported value, this approach resulted in an $\sim 2$ fold enhancement of IP production using Pichia based expression systems, thus significantly increasing the efficiency of insulin manufacture.
\end{abstract}

\section{Background}

Diabetes is a progressive disease characterized by hyperglycemia, resulting from defects in insulin secretion, its function, or both. The long-term effects of this disease, for which there is no cure, lead to multiple organ damage and failure [1]. The World Health Organization estimates that $\sim 2.9$ million deaths are attributable to diabetes every year [2]. Based on demographic changes, it has been estimated that the number of diabetics around the world,

\footnotetext{
*Correspondence: ursula.rinas@helmholtz-hzi.de

1 Helmholtz Centre for Infection Research, Braunschweig, Germany Full list of author information is available at the end of the article
}

which was $\sim 171$ million at the turn of this century, will more than double by the year 2030 [3]. This is likely to be an underestimate given that factors, such as improved life expectancy and obesity contributing to increased prevalence of diabetes, have not been taken into consideration.

Insulin is a 51 amino acid (aa) polypeptide hormone essential for normal glucose homeostasis and is therefore useful in treating diabetes. Insulin contains two polypeptide chains, A (21 aa) and B (30 aa), with three disulfide bonds. Two of these interlink the A- and B-chains, while the third one is an intra A-chain bond [4,5]. Though, initially, insulin was isolated from porcine pancreas, the 
advent of recombinant DNA technology helped to address the requirement for insulin more effectively. However, commensurate with the projected escalation in the prevalence of diabetes in the coming decades [3], there will be an increasing demand for insulin. To meet this, more cost-effective biotechnological strategies for recombinant insulin production are required.

Insulin was the first recombinant product approved by the FDA for human application [6,7]. The first expression systems were based on the separate expression of the Aand B-chains fused to carrier proteins in two different $E$. coli strains $[8,9]$. Nowadays, human insulin is produced as recombinant protein, using two major routes. One route involves the production of an insulin precursor in the form of inclusion bodies, using $E$. coli as expression host with subsequent solubilization and refolding procedures [10]. The other route involves the utilization of yeastbased expression systems, leading to the secretion of a soluble insulin precursor (IP) into the culture supernatant [11-13]. Both routes are economically viable. Due to the extensive experience in large-scale cultivation, Saccharomyces cerevisiae became the first yeast-based expression system for secretory IP production [11,12]. Though S. cerevisiae is still the predominant yeast system for insulin production, several alternative yeast hosts have become available in recent years [14-18]. Of these, the methylotrophic yeast Pichia pastoris has emerged as a very useful expression host with superior features [1821]. In particular, its reliance on integrative vectors, its strong and tightly regulated methanol-inducible alcohol oxidase $1(A O X 1)$ promoter and its capacity to reach very high cell densities by simple cultivation strategies collectively contribute to stable and high level production of recombinant proteins.

Several reports have also demonstrated the utility of $P$. pastoris for secretory IP production [22-30]. The yields reported so far vary over a wide range, with the highest being 1.5 gram IP per liter of culture broth (Table 1). Thus, $P$. pastoris has proven its applicability for insulin production, and, in fact, a comparative study revealed an equal or even better performance of $P$. pastoris compared to $S$. cerevisiae [22].

For secretory IP production using $P$. pastoris as host, the $S$. cerevisiae based $\alpha$-factor pre-pro leader is most often employed as secretion signal [13]. In general, the insulin B- and A-chains are joined by a short connecting peptide linker, which allows tryptic precursor processing for generation of human insulin [22,25,26,31]. Secretion yields of the single chain insulin precursors can be enhanced by adding a charged synthetic spacer peptide in front of the insulin B-chain segment, which allows more efficient Kex2 endoprotease processing after the $\alpha$-factor pre-pro leader $[13,22,32]$. After recovery from the culture broth, IP can be converted enzymatically into human insulin $[26,27,29,33,34]$.

We recently devised a robust cultivation strategy for high-level intracellular production of the Hepatitis B surface antigen (HBsAg), using P. pastoris as expression host [35]. In this procedure, cells were first grown to high-cell density in a batch process, using a simple defined medium with low salt and high glycerol concentrations. After batch growth, induction of high-level product formation was achieved by adding methanol to a final concentration of $6 \mathrm{~g} \mathrm{~L}^{-1}$ and keeping this high concentration for the remainder of the production phase. In the present work, we have adapted this strategy to secretory IP production. Further, we also present a novel purification procedure, based on the metal binding affinity of IP and, finally, describe the conversion of the insulin precursor to human insulin of high purity by enzymatic and chemical processing.

\section{Results}

\section{Construction of the IP-secreting P. pastoris clone}

The IP encoding gene, codon-optimized for expression in $P$. pastoris, was obtained by chemical synthesis. The polypeptide encoded by this gene carries at the N-terminus 4 amino acids corresponding to the carboxy-terminal part of the $S$. cerevisiae $\alpha$-factor secretory signal (LEKR) which contains the Kex2 cleavage site, followed by a spacer peptide (EEAEAEAEPK) for more efficient Kex2 processing and secretion, followed by the insulin $\mathrm{B}$ chain amino acids 1-29, a short connecting linker (AAK), and finally the insulin A chain amino acids 1-21. This gene was fused in-frame with the $S$. cerevisiae $\alpha$-factor secretory signal in the Pichia integrative vector $\mathrm{pPICZ} \alpha$ to generate the expression plasmid pPICZ $\alpha$-IP (Fig. 1). The IP gene carries its own stop codon and, consequently, does not contain the vector-encoded carboxy-terminal $c$ $m y c$ and $\mathrm{His}_{6}$ tags. The IP secreted by this vector, following Kex 2 cleavage, is predicted to be 63 amino acids long with a molecular mass of $\sim 7 \mathrm{kDa}$. The plasmid pPICZ $\alpha$ IP was linearized with $S a c$ I and electroporated into $P$. pastoris strain $\mathrm{X}-33$ and the resulting transformants selected on zeocin plates, containing progressively increasing concentrations of zeocin $\left(0.1-2.0 \mathrm{mg} \mathrm{mL}^{-1}\right)$ to identify multicopy clones. The maximum zeocin concentration at which clones could be recovered was $0.5 \mathrm{mg}$ $\mathrm{mL}^{-1}$. Several clones that were viable at this zeocin concentration were tested in small scale induction experiments. Extracellular IP concentrations were analyzed by RP-HPLC to identify the best expressing clone. The methanol utilization phenotype of this clone was found to be $\mathrm{Mut}^{+}$, indicating that integration had occurred at the AOX1 locus by a single crossover event. 
Table 1: Insulin precursor production with $P$. pastoris

\begin{tabular}{|c|c|c|c|c|c|c|c|}
\hline Strain (copy\#) & $\begin{array}{l}\text { MeOH } \\
(\%)\end{array}$ & $\begin{array}{l}\text { Induction time } \\
\text { (h) }\end{array}$ & $\begin{array}{l}\text { Final biomass } \\
\left(g^{-1}\right)\end{array}$ & $\begin{array}{l}\text { Product a } \\
\left(g^{-1}\right) \\
\text { Culture supernatant }\end{array}$ & $\begin{array}{l}\text { Product b } \\
\left(g^{-1}\right) \\
\text { Culture broth }\end{array}$ & Mass & Reference $^{c}$ \\
\hline $\mathrm{Mut}^{+/ s}(6-8)$ & nd d & 87 & nd & 1.5 & nd & nd & {$[26]$} \\
\hline $\operatorname{Mut}^{s}(\mathrm{nd})$ & 1.0 & 72 & 80 to 90 & 0.22 & nd & nd & {$[25]$} \\
\hline $\operatorname{Mut}^{s}(11)$ & $<0.1$ & 110 & 89 & 0.3 & nd & MS e & {$[24]$} \\
\hline Muts $^{s}(11)$ & 1 to 0.5 & 136 & 109 & 0.25 & nd & MS & {$[23]$} \\
\hline $\operatorname{Mut}^{s}(\mathrm{nd})$ & nd & 72 & nd & 3.6 & 1.47 & nd & [27] \\
\hline $\mathrm{Mut}^{+}(12)$ & 0.8 & 96 & nd & 0.18 & nd & nd & {$[28]$} \\
\hline $\operatorname{Mut}^{+}(\sim 2)^{f}$ & 0.2 & 88 & 59 & 3.84 & 3.075 & MS & Present study \\
\hline $\begin{array}{l}\text { a Concentration } \\
\text { b Concentration } \\
\text { c Only reference } \\
\text { d nd; not determ } \\
\text { e MS; mass spec }\end{array}$ & $\begin{array}{l}\text { were dete } \\
\text { calculatec } \\
\text { on secretc } \\
\text { hed }\end{array}$ & $\begin{array}{l}\text { ined by reverse } \mathrm{p} \\
\text { onsidering the vol } \\
\text { insulin precursor }\end{array}$ & $\begin{array}{l}\text { ase HPLC from cla } \\
\text { metric portion of } \\
\text { roduction with } P \text {. }\end{array}$ & $\begin{array}{l}\text { fied culture supernatant } \\
\text { omass in the culture bro } \\
\text { astoris included containi }\end{array}$ & respective quant & e data & \\
\hline
\end{tabular}

\section{Production of IP in fed-batch culture}

Initial attempts for secretory production of IP were based on the direct application of the fed-batch procedure recently developed for high-level intracellular production of HBsAg with P. pastoris [35]. Employing these conditions, cells were first grown in a batch procedure using a simple defined medium with low salt and high glycerol concentrations. After depletion of glycerol, induction of product formation was achieved by adding methanol to a final concentration of $6 \mathrm{~g} \mathrm{~L}^{-1}$ and keeping this high concentration for the remainder of the production phase. This methanol concentration was very efficient for the intracellular production of HBsAg leading only to minor temporary growth arrest [35], however, these conditions

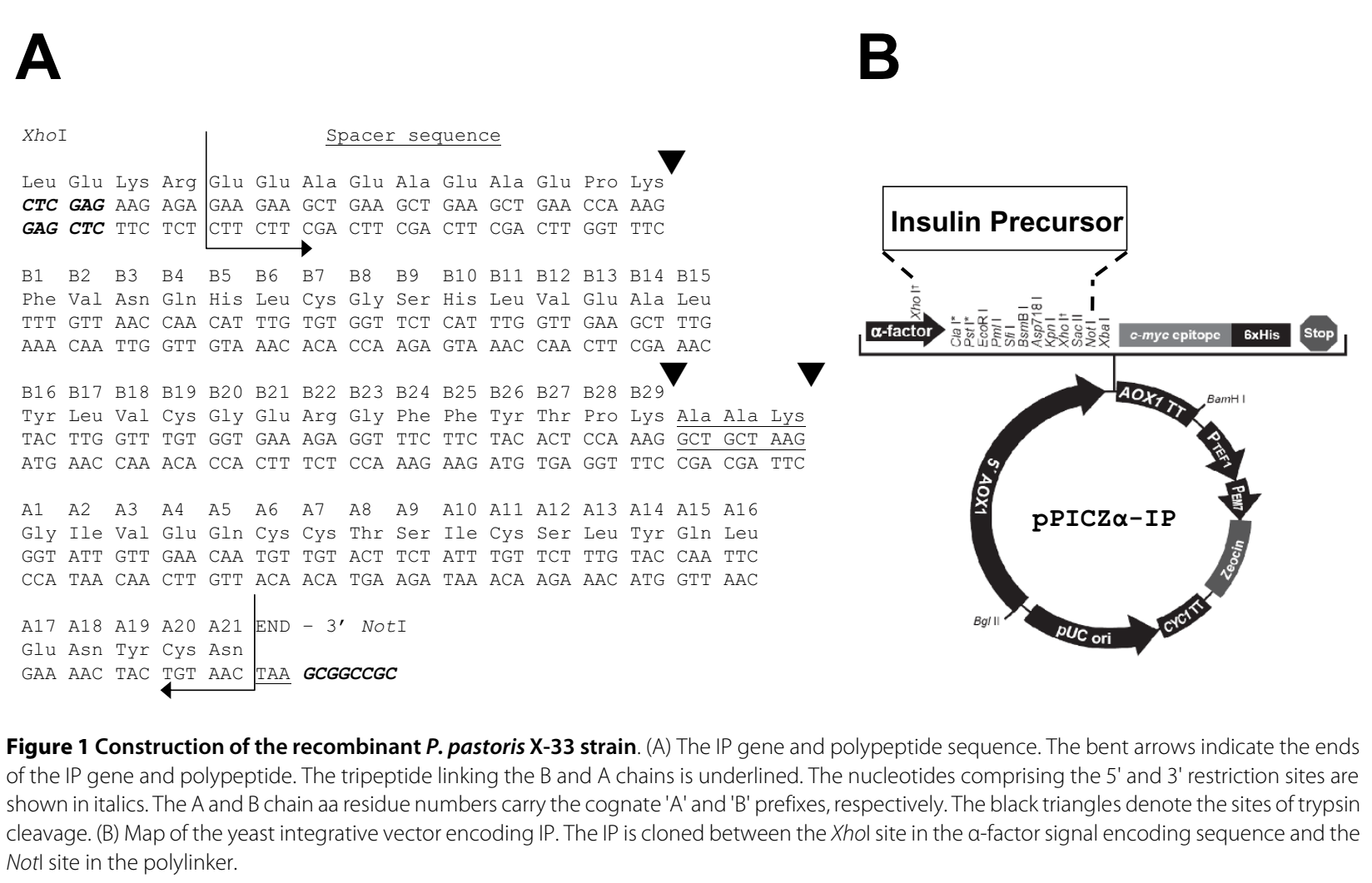


were detrimental for the secretory production of IP. In this case, addition of methanol to final concentrations of $6 \mathrm{~g} \mathrm{~L}^{-1}$ was leading to a drastical drop of the optical density concomitant to foam formation indicative of profound cell lysis (data not shown). Moreover, base consumption was replaced by acid consumption indicating the formation and/or release of alkaline compounds. Finally, cultivations had to be discontinued 10-15 h after methanol addition due to uncontrollable foaming.

Thus, we aimed at less drastic conditions to induce the secretory production of IP. After the depletion of glycerol (Fig. 2A), methanol was first added to a final concentration of $1 \mathrm{~g} \mathrm{~L}^{-1}$ (Fig. 2B). With some time delay the cellular adjustment to methanol utilization was noticeable by a slight increase in the culture $\mathrm{pH}$ followed by acid addition for culture $\mathrm{pH}$ maintenance (Fig. 2C) and a decrease in the respiratory activity (Fig. 2D and 2E). Successful adaptation to methanol was then evident by the onset of methanol consumption (Fig. 2B) and the increase of the respiratory activity which started $\sim 4$ hours after methanol addition (Fig. 2D and 2E). About 20 and $24 \mathrm{~h}$ after the initial methanol pulse, the concentration of methanol in the bioreactor was further increased to 1.5 and $2 \mathrm{~g} \mathrm{~L}^{-1}$, respectively, and kept constant for the remainder of the cultivation without causing noteworthy process pertubations, e.g. uncontrollable foaming (Fig. 2B). The biomass concentration showed only a slight increase after the shift to methanol, increasing from 56 to $59 \mathrm{~g} \mathrm{~L}^{-1}$ and starting to decline again after about $120 \mathrm{~h}$ growth on methanol (Fig. 2A).

Recombinant IP production was analyzed by RP-HPLC and SDS-PAGE during the induction phase from culture aliquots withdrawn at various time points (Fig. $2 \mathrm{~F}$ and 3 , respectively). Extracellular IP concentrations increased during the first $80 \mathrm{~h}$ of growth on methanol reaching a maximum of 3.075 gram per liter of culture broth. Taking

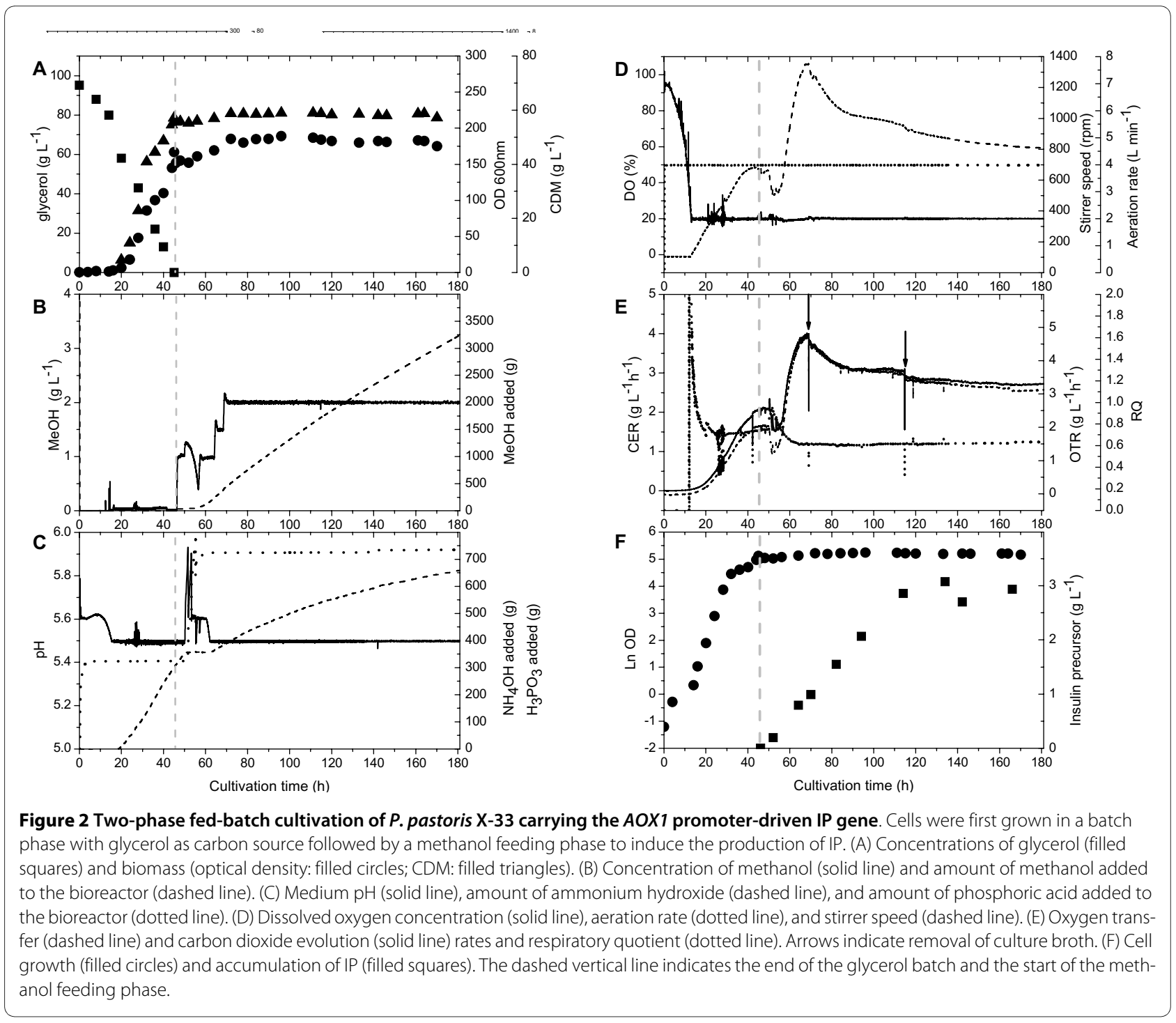




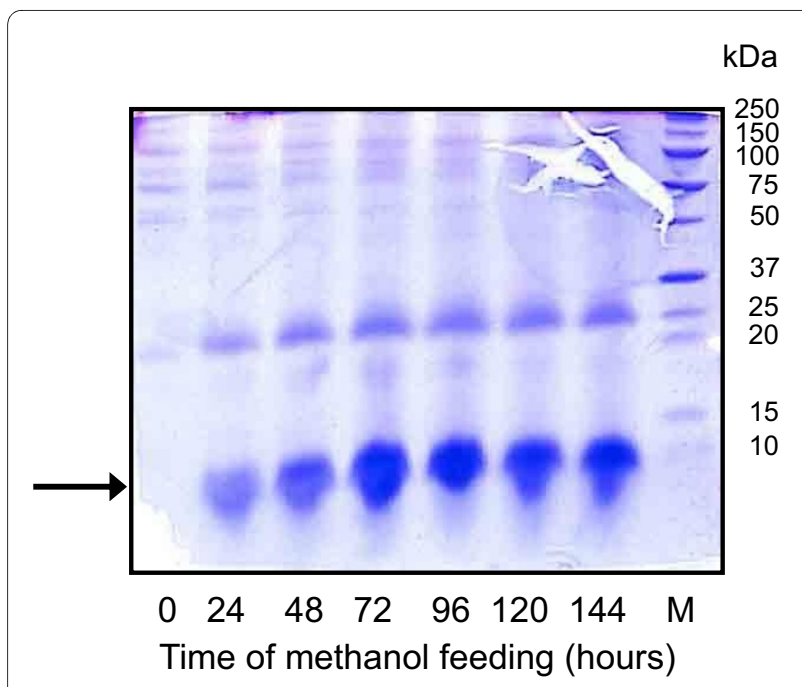

Figure 3 Time course analysis of secretory IP production. Cell-free culture supernatants were analyzed by $10 \%$ Tricine SDS-PAGE from samples taken directly before the addition of methanol (time 0 ) and 24 , $48,72,96,120$ and 144 hours after the onset of methanol feeding. The arrow denotes the position of IP and $\mathrm{M}$ the lane of the molecular weight marker.

into account that the culture broth contained about $20 \%$ $(\mathrm{v} / \mathrm{v})$ biomass and $80 \%(\mathrm{v} / \mathrm{v})$ cell free culture supernatant, the concentration of $\sim 3$ gram IP per liter culture broth translates into almost 4 gram IP per liter culture supernatant. Absence of excessive foaming and equal high product yields were also reached when the methanol concentration was immediately increased to a final concentration of $2 \mathrm{~g} \mathrm{~L}^{-1}$ at the end of the glycerol batch phase (data not shown). Degradation of IP was not observed during the whole process. SDS-PAGE analysis of culture supernatants revealed that IP accumulated as the most prominent extracellular protein (Fig. 3).

\section{Purification of IP from the culture broth}

Two different purification procedures were employed for the purification of IP from the culture broth. First, we aimed at the separation of the insulin precursor from the crude culture broth by using expanded bed absorption. This procedure omits the clarification of the culture broth by centrifugation and filtration, thus simplifying the down-stream process. To allow binding of the insulin precursor (theoretical $\mathrm{p} I$ 4.74) to the resin in the expanded bed column, it was necessary to dilute and acidify the culture broth. After loading and washing the column in the expanded bed mode, the bound IP was eluted in normal mode using $1 \mathrm{~mol} \mathrm{~L}^{-1} \mathrm{NaCl}$. The recovery of IP was not satisfactory, however, it could be increased two fold by supplementing the dilutent with the detergent Tween 20, which allowed more efficient binding and elution of IP from the resin. Under optimized conditions, $\sim 1.5 \mathrm{~g}$ IP with a purity of $97 \%$ could be recovered from one liter culture broth, using expanded bed adsorption chromatography (Table 2).

Furthermore, we wanted to explore if the natural metal binding affinities of human insulin and proinsulin [36-38] could be exploited for an immobilized metal affinity chromatography (IMAC) based purification step. Preliminary tests revealed that the insulin precursor can bind to IMAC columns precharged with $\mathrm{Cu}^{2+}$ and $\mathrm{Ni}^{2+}$ but - in contrast to insulin - not to $\mathrm{Zn}^{2+}$-precharged columns. Thus, the clarified culture broth was passed through $\mathrm{Cu}^{2+}$ pre-charged chelating sepharose fast flow (GE Healthcare) and, after extensive washing to remove unbound impurities, the bound insulin precursor could be eluted at

Table 2: Purification of insulin precursor from microbial cultures

\begin{tabular}{|c|c|c|c|c|}
\hline Expression host & Chromatography matrix & Recovery (\%) a & Purity (\%) a & Reference $^{b}$ \\
\hline E. colic & IgG-Sepharose & 90 & nd d & {$[10]$} \\
\hline S. cerevisiae & $\begin{array}{l}\text { Streamline SP }(\mathrm{XL}) \\
\text { Expanded bed adsorption }\end{array}$ & 88 & nd & {$[43]$} \\
\hline P. pastoris & $\begin{array}{l}\text { XAD-7T } \\
\text { Sephadex-G50 }\end{array}$ & $>80^{\mathrm{e}}$ & $60 \mathrm{e}$ & {$[26]$} \\
\hline P. pastoris & CM-Sepharose FF & 97 & 97 & {$[27]$} \\
\hline P. pastoris & $\begin{array}{l}\text { Streamline SP }(\mathrm{XL}) \\
\text { Expanded bed adsorption }\end{array}$ & 55 & 97 & Present study \\
\hline P. pastoris & IMAC-coupled with copper ions & 95 & 96 & Present study \\
\hline
\end{tabular}

a Recovery and purity relates to the first chromatographic step

b Only references on insulin precursor purification included containing respective quantitative data

c Insulin precursor fused to lg G binding domains produced in the form of inclusion bodies

d nd; not determined

e Recovery and purity relates to the two-step purification procedure 
low $\mathrm{pH}$. This step resulted in a recovery of $95 \%$ IP with a purity of $96 \%$ (Table 2, Fig. 4A).

\section{Conversion of IP to human insulin}

The insulin precursor was transformed into pre-insulin by enzymatic transpeptidation in the presence of trypsin and $\mathrm{O}$-t-butyl-L-threonine $\mathrm{t}$-butyl ester $(\mathrm{H}-\mathrm{Thr}(\mathrm{tBu})$ $\mathrm{OtBu})$. During this reaction, the $\mathrm{N}$-terminal spacer peptide (EEAEAEAEPK) and the connecting linker peptide (AAK) are removed (Fig. 1A) and the threonine ester is added to B-29 in a transesterification reaction [33]. The efficiency of this reaction is around $90 \%$. There are three species formed during the transpeptidation reaction which can be detected by analytical RP-HPLC (Fig. 4B). These species elute at retention times $21.8 \mathrm{~min}, 23.5 \mathrm{~min}$, and $29.1 \mathrm{~min}$ and correspond to B22 cleaved IP, B29 cleaved IP without the threonine ester, and the desired reaction product pre-insulin- $\mathrm{Thr}(\mathrm{tBu})-\mathrm{OtBu}$ (pre-insu- lin), respectively. B22 cleaved IP and B29 cleaved IP without the threonine ester represent only minor contaminants, the majority of IP is transformed into preinsulin (Fig. 4B). Pre-insulin was purified from the transesterification mixture using semi-preparative gradient chromatography (Resource RPC column, Table 3).

The final recombinant human insulin was obtained from pre-insulin by removal of the blocking tertiary butyl groups from threonine in position B30 by acidolysis with trifluoroacetic acid (deprotection reaction). This step was tested at different temperatures (RT, ice, $10^{\circ} \mathrm{C}$ ) and incubation times (from $30 \mathrm{~min}$ to $4 \mathrm{~h}$ ). The highest yields were reached at RT with a reaction time of $60 \mathrm{~min}$. After 60 min, more than $90 \%$ of pre-insulin is converted to human insulin (Fig. 4D). Only a minor fraction $(\sim 2 \%)$ of preinsulin is converted into undesired by-products such as A21 desamido insulin. Finally, recombinant human insulin was purified by RP-HPLC as described in the Materi-
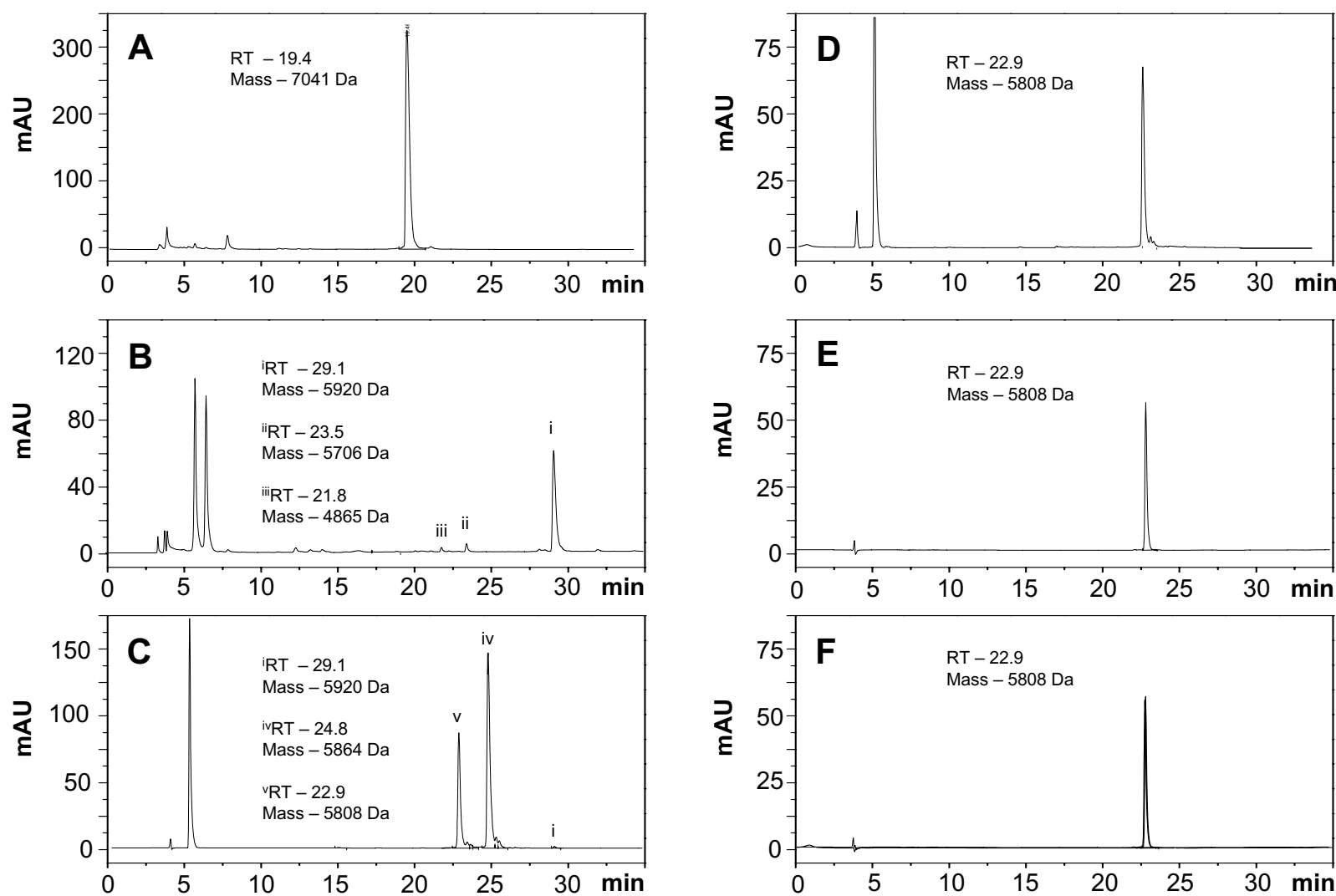

Figure 4 RP-HPLC profiles of insulin species recovered after IMAC, transpeptidation and deprotection reactions, and final purification. (A) RP-HPLC profile of the purified IP from IMAC. IP was eluted at a retention time of 19.4 minutes. (B) RP-HPLC profile of insulin species recovered after the transpeptidation reaction with i) pre-insulin $\mathrm{H}-\mathrm{Thr}(\mathrm{tBu})-\mathrm{O}+\mathrm{Bu}$; ii) insulin species cleaved at B29 without the threonine ester; and iii) Insulin species cleaved at B22. (C) RP-HPLC profile of deprotection reaction in which the pre-insulin reaction mixture was incubated at room temperature for 5 minutes, with i) pre-insulin H-Thr(tBu)-OtBu; iv) insulin Thr-OtBu; and v) human insulin. (D) RP-HPLC profile of deprotection reaction in which the pre-insulin reaction mixture was incubated at room temperature for 60 minutes (E) RP-HPLC profile of purified human insulin. (F) RP-HPLC profile of mixture of human insulin and European Pharmacopoeia human insulin standard. The Phenomenex Jupiter C4 column was employed for quantification of insulin species. The identity of insulin species was determined by mass spectrometry as specified in the Materials and Methods section. 
Table 3: Purification of insulin precursor by IMAC and conversion to human insulin

\begin{tabular}{|c|c|c|c|c|c|}
\hline Steps & $\begin{array}{l}\text { Insulin species } \\
\text { (molecular mass) }\end{array}$ & Amount (mg) a & Amount (mmol) a & Recovery (\%) a & Purity (\%) a \\
\hline Culture broth $\mathrm{b}$ & $\begin{array}{l}\text { Insulin precursor } \\
7041 \mathrm{Da}\end{array}$ & 3075 & 0.437 & 100 & 20 \\
\hline Chelating sepharose FF c & $\begin{array}{l}\text { Insulin precursor } \\
7041 \mathrm{Da}\end{array}$ & 2921 & 0.415 & 95 & 96 \\
\hline Desalting \& Lyophilization & $\begin{array}{l}\text { Insulin precursor } \\
7041 \mathrm{Da}\end{array}$ & 2859 & 0.406 & 93 & 98 \\
\hline Transpeptidation & $\begin{array}{l}\text { Pre-insulin } \\
5920 \mathrm{Da}\end{array}$ & n.d. d & n.d. ${ }^{d}$ & n.d. $d$ & n.d. $d$ \\
\hline $\begin{array}{l}\text { Resource RPC Desalting \& } \\
\text { Lyophilization }\end{array}$ & $\begin{array}{l}\text { Pre-insulin } \\
5920 \mathrm{Da}\end{array}$ & 1915 & 0.323 & 74 & 90 \\
\hline Deprotection & $\begin{array}{l}\text { Human insulin } \\
5808 \mathrm{Da}\end{array}$ & n.d. d & n.d. ${ }^{d}$ & n.d. $d$ & n.d. d \\
\hline $\begin{array}{l}\text { Resource RPC (two } \\
\text { passages), Desalting \& } \\
\text { Lyophilization }\end{array}$ & $\begin{array}{l}\text { Human insulin } \\
5808 \mathrm{Da}\end{array}$ & 1537 & 0.264 & 60 & 99 \\
\hline $\begin{array}{l}\text { a Recovery and purity was d } \\
\text { b } 200 \text { mg of IP were used for } \\
\text { c Centrifugation step includ } \\
\text { d n.d., not determined }\end{array}$ & $\begin{array}{l}\text { ined by RP-HPLC } \\
\text { er processing. Data } \\
\text { ore chromatograph }\end{array}$ & polated to $1-\mathrm{L} \mathrm{Cu}$ & e broth & & \\
\hline
\end{tabular}

als and Methods section. During this step, the A21 desamido insulin and other impurities are removed raising the purity of human insulin to $99 \%$ as determined by RP-HPLC (Fig. 4E) fully satisfying the European Pharmacopoeia requirements [39]. The total yield of the described process is around $60 \%$ (Table 3 ).

\section{Discussion}

Production of recombinant proteins can be stressful to the host organism [40]. Compared to the intracellular production of HBsAg [35], the secretory production of IP is more harmful to the cells. Using high methanol concentrations for induction, extensive cell lysis is observed in the case of extracellular IP production but not in the case of the intracellular production of HBsAg. Although the extent of the cellular stress response is influenced by the nature of the recombinant product, membrane damage associated cell lysis is more likely to occur when the recombinant protein is directed towards the extracellular environment compared to intracellular product retention. In case of secretory protein production, less harsh induction conditions might be more advantageous to reduce growth perturbations to acceptable levels while keeping production levels high. For secretory IP production with $P$. pastoris, induction at a final methanol concentration of $2 \mathrm{~g} \mathrm{~L}^{-1}$ is appropriate for high level production. This methanol concentration does not cause cell lysis and only leads to a neglectable increase in bio- mass during the production phase, thus, leading to optimal conditions for the recovery of proteins from the extracellular environment.

In conclusion, a simple two-phase cultivation process composed of a glycerol batch and a constant methanol fed-batch phase was adapted to secretory IP production. This approach increases IP levels more than 2 times compared to the highest previously reported value using Pichia based expression systems. Moreover, we propose a novel procedure to capture the insulin precursor from the culture supernatant using IMAC and, finally, show that $\sim 1.5 \mathrm{~g}$ of $99 \%$ pure recombinant human insulin can be obtained per liter of culture broth.

\section{Materials and methods Strains and vectors}

P. pastoris host strain $\mathrm{X}-33$ and the plasmid vector pPICZ $\alpha$ were purchased from Invitrogen. Plasmid pPICZ $\alpha$ (Invitrogen Cat. No. V195-20) was used to construct the methanol inducible IP expression vector. A synthetic codon-optimized gene encoding the IP was inserted into the polylinker of this vector, in-frame with the $\alpha$-factor secretion signal sequence to create the expression plasmid pPICZ $\alpha$-IP, which was then integrated into the genome of $P$. pastoris strain X-33. Transformation of Pichia, selection and screening of transformants to identify clones harboring the IP inserts, the isolation of putative multicopy clones using the zeo- 
cin screening protocol, and the identification of the methanol utilization ( $m u t$ ) phenotype were performed essentially as described previously [41].

\section{Culture conditions, control and on-line measurements}

Precultures for high-cell density bioreactor cultivations were prepared as described before [35]. High-cell density cultivations were carried out in a 15-L BIOSTAT-C (B. Braun Biotech International, Germany) bioreactor essentially as described previously [35] with minor modifications. A 1-L preculture was transferred to the bioreactor containing $7 \mathrm{~L}$ growth medium. The growth medium contained per liter: glycerol, 95.2 g; potassium di-hydrogen phosphate, 9.4 g; yeast trace metal (YTM) solution, $4.56 \mathrm{~g}$; ammonium sulfate, $15.7 \mathrm{~g}$; magnesium sulfate hepta-hydrate, $4.6 \mathrm{~g}$; calcium chloride di-hydrate, $0.28 \mathrm{~g}$; and biotin, $0.4 \mathrm{mg}$. The YTM solution contained: potassium iodide, $207.5 \mathrm{mg} \mathrm{L}^{-1}$; manganese sulfate, $760.6 \mathrm{mg} \mathrm{L}$ 1; di-sodium molybdate, $484 \mathrm{mg} \mathrm{L}^{-1}$; boric acid, $46.3 \mathrm{mg} \mathrm{L}$ 1; zinc sulfate hepta-hydrate, $5.032 \mathrm{~g} \mathrm{~L}^{-1}$; ferric chloride hexa-hydrate, $12.0 \mathrm{~g} \mathrm{~L}^{-1}$; and sulfuric acid, $9.2 \mathrm{~g} \mathrm{~L}^{-1}$. Foaming was controlled by the addition of antifoam (Ucolub N115). Temperature was maintained at $30^{\circ} \mathrm{C}$ and $\mathrm{pH}$ at $\mathrm{pH} 5.5$ with $12.5 \%(\mathrm{v} / \mathrm{v}) \mathrm{NH}_{4} \mathrm{OH}$ or $1 \mathrm{~mol} \mathrm{~L}^{-1}$ $\mathrm{H}_{3} \mathrm{PO}_{4}$. Aeration rate was maintained at $4 \mathrm{~L} \mathrm{min-1}$ throughout the process. The stirrer speed was controlled between 100 to $1370 \mathrm{rpm}$ aiming at a dissolved oxygen (DO) concentration of $20 \%$ air saturation. After consumption of glycerol, indicated by an increase of the DO concentration, production of recombinant IP was initiated by step-wise addition of a methanol solution [96.6\% $(\mathrm{w} / \mathrm{w})$ methanol and $4.4 \%(\mathrm{w} / \mathrm{w}) \mathrm{YTM}$ ] to a final methanol concentration of $2 \mathrm{~g} \mathrm{~L}^{-1}$, which was maintained constant throughout the remainder of the induction period based on on-line measured methanol concentrations determined from the methanol vapor in the off-gas using a flame ionization detector (Ratfish Instruments, Germany). Based on the gas liquid phase equilibrium methanol concentrations were determined in the off-gas using two point calibrations directly before and after induction. The concentrations of oxygen and carbon dioxide in the exhaust gas were determined by paramagnetic and infrared exhaust gas analysis systems, respectively (Maihak, Hamburg, Germany).

\section{Determination of cell concentration}

The cell concentration of suitably diluted culture samples was measured by optical density (OD) at $600 \mathrm{~nm}$ using a Novaspec II spectrophotometer (Pharmacia LKB). For cell dry mass (CDM) determination, 1-mL aliquots of the culture broth were pelleted $(13,000 \mathrm{rpm}$ for $15 \mathrm{~min}$ at room temperature using an Eppendorf microcentrifuge, model $5415 \mathrm{C}$ ) in pre-weighed tubes, re-suspended in 50 mmol L-1 phosphate buffer ( $\mathrm{pH} 7.2)$, re-centrifuged and the resultant pellets vacuum-dried at $80^{\circ} \mathrm{C}$ (Heraeus Instruments, Vacutherm) to constant mass. CDM was measured in triplicates and averaged.

\section{Determination of glycerol concentration}

Culture samples $(1-\mathrm{mL})$ were centrifuged $(13,000 \mathrm{rpm}$ for $15 \mathrm{~min}$ at $4^{\circ} \mathrm{C}$ ) and the glycerol concentration in the supernatant analyzed in duplicate using glycerol test kits (Roche, Basel, Switzerland).

\section{Protein analysis}

Clarified culture broth samples were analyzed by denaturing 10\%-polyacrylamide gel electrophoresis using the Tricine buffer system [42]. Samples $(40-\mu \mathrm{L})$ were mixed with an equal volume of loading buffer $\left[250 \mathrm{mmol} \mathrm{L}^{-1} \mathrm{Tri}-\right.$ cine ( $\mathrm{pH} 8.5), 10 \% \beta$-mercaptoethanol, $2 \%$ SDS, $1 \%$ glycerol, and $0.1 \%$ bromophenol blue], vortexed for $1 \mathrm{~min}$ and boiled for $15 \mathrm{~min}$, vortexed again, clarified by centrifugation (max speed, $15 \mathrm{~min}, \mathrm{RT})$ and loaded on the gel $(20 \mu \mathrm{L}$ per lane). Following electrophoresis, the separated polypeptides were visualized using Coomassie blue staining.

Reversed-phase HPLC (RP-HPLC) was used for quantification of IP from culture broth. Filtered aliquots of Pichia culture broth $(200-\mu \mathrm{L})$ were mixed with an equal volume of solution A [0.15\% (v/v) TFA in MilliQ water] and analyzed by RP-HPLC using a $3 \mu \mathrm{m}$ SUPELCOSIL $^{\mathrm{Tm}}$ LC-304 column $(3.3 \mathrm{~cm} \times 4.6 \mathrm{~mm})$ with a Schimadzu liquid chromatography system, equipped with an autoinjector (SIL-10AD VP), UV-VIS detector (SPD-10A), pumps $\mathrm{A}$ and $\mathrm{B}$ (LC-10AT $V P$ ), and a controller (SCL$10 \mathrm{~A} V P)$. The HPLC column was maintained at $24^{\circ} \mathrm{C}$ (HPLC column oven, CH-500, Eppendorf, Germany). Elution was done with a gradient formed by mixing solutions $A$ and $B[0.15 \%(v / v)$ TFA in acetonitrile] as follows: $10 \%$ B (0 - 6 min), 10 - 43\% B (6 - $41 \mathrm{~min}), 43$ - 100\% B (41 - $43 \mathrm{~min}), 100$ - 10\% B (43 - $53 \mathrm{~min}), 10 \%$ B (53 - $60 \mathrm{~min}$ ). The flow rate was maintained at $1 \mathrm{~mL} \mathrm{~min}^{-1}$. The column effluent was monitored at $280 \mathrm{~nm}$.

Reversed-phase HPLC (RP-HPLC) was also used for characterization and quantification of IP and insulin species after purifications, transpeptidation, and deprotection. These samples were loaded on a $5 \mu \mathrm{m}$ Phenomenex Jupiter C4 column (300A, $250 \mathrm{~mm} \times 4.6 \mathrm{~mm})$ in solution A $[0.1 \%(v / v)$ TFA in MilliQ water]. Elution was done at $25^{\circ} \mathrm{C}$ with a gradient formed by mixing solutions $\mathrm{A}$ and $\mathrm{B}$ [0.1\% (v/v) TFA in acetonitrile] as follows: $0-20 \%$ B (0 - 6 min), 20 - 55\% B (6 - $41 \mathrm{~min}), 55-100 \%$ B (41 - $42 \mathrm{~min})$.

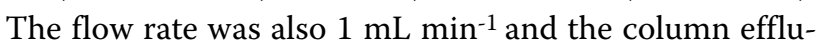
ent was monitored at $280 \mathrm{~nm}$.

\section{Purification of IP using expanded bed absorption}

The culture broth (1-L) was diluted with 4 liter of $1 \%$

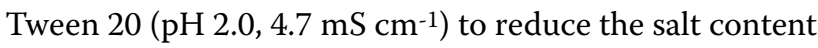
(conductivity of culture broth was $24.2 \mathrm{mS} \mathrm{cm}^{-1}$ ), the $\mathrm{pH}$ and the viscosity for more efficient binding to the Stream- 
line SP XL resin (Amersham Pharmacia Biotech, Sweden). A Streamline 50 column (Amersham Pharmacia Biotech, Sweden) packed with Streamline SP XL resin to a sedimented height of $13 \mathrm{~cm}$ and pre-equilibrated with $1 \%$ Tween 20 ( $\mathrm{pH} 2.0 ; 4.7 \mathrm{mS} \mathrm{cm}^{-1}$ ) was employed and the diluted and well mixed culture broth was pumped from the lower end of the column leading to an expansion of the sedimented height to $24.4 \mathrm{~cm}\left(H / H_{o}\right.$ expansion ratio $=$ 1.88 , where $H$ and $H_{o}$ represent the heights of the column bed after and before expansion, respectively). After loading, the column was washed with MilliQ water ( $\mathrm{pH} 5.8$ ) until the absorbance at $280 \mathrm{~nm}$ returned to base line in the eluate. Following, the bound IP was eluted using conventional chromatography by reversing the flow in a now settled bed using $1 \mathrm{~mol} \mathrm{~L}^{-1} \mathrm{NaCl}(\mathrm{pH} \mathrm{7.5}$, conductivity $\sim 100 \mathrm{mS} \mathrm{cm}^{-1}$ ). Protein containing fractions (absorbance at $280 \mathrm{~nm}$ ) were pooled and loaded on a preparative C18 bulk column (125 A $\mathrm{A}^{0} 55-105 \mu \mathrm{m}$, Waters Corporation, Milford, MA, USA) pre-equilibrated with $10 \%$ acetonitrile and $0.1 \%$ TFA. After loading, the column was washed with $10 \%$ acetonitrile and $0.1 \%$ TFA and elution was carried out with $60 \%$ acetonitrile and $0.1 \%$ TFA. The eluted protein was lyophilized prior to further treatment (Labconco freeze dry system, Germany).

\section{Purification of IP using íon metal affinity chromatography}

The culture broth (1-L) was centrifuged (Sorvall RC5BPlus centrifuge, SLA 3000 rotor) at $4^{\circ} \mathrm{C}$ and 3,000 $\mathrm{rpm}$ for $30 \mathrm{~min}$. The supernatant was filtered using a 0.22 $\mu \mathrm{m}$ filter, the $\mathrm{pH}$ adjusted to $\mathrm{pH} 7.0$ and the clarified culture supernatant allowed to bind to $\mathrm{Cu}^{2+}$ pre-charged chelating sepharose fast flow (GE Healthcare) pre-equilibrated in equilibration buffer $[20 \mathrm{mmol} \mathrm{L}-1$ sodium phosphate buffer ( $\mathrm{pH} 7.0$ ), $500 \mathrm{mmol} \mathrm{L} \mathrm{maCl}^{-1} \mathrm{Nat}$ room temperature. A maximum of $200 \mathrm{mg}$ IP was used per 50 $\mathrm{mL}$ column volume. After sample loading, the column was extensively washed with equilibration buffer to remove unbound proteins. The bound IP was eluted by a linear $\mathrm{pH}$ gradient using a low $\mathrm{pH}$ elution buffer [20 mmol L-1 sodium phosphate buffer ( $\mathrm{pH} 3.15$ ), $500 \mathrm{mmol}$ $\mathrm{L}^{-1} \mathrm{NaCl}$. The purified IP was diluted with MilliQ water to lower the conductivity to appr. $8 \mathrm{mS} \mathrm{cm}^{-1}$ and the $\mathrm{pH}$ adjusted to $\mathrm{pH} 4.0$ to allow binding to HiTrap SP HP column (GE Healthcare). Elution was performed using 100 mmol L-1 $\mathrm{NH}_{4} \mathrm{HCO}_{3}$ (pH 9.0). The purified IP was lyophilized prior to the conversion to pre-insulin by transpeptidation.

\section{Transpeptidation, deprotection and final purification of human insulin}

The transpeptidation reaction was essentially performed as described previously [33] with minor modifications. Briefly, the reaction mixture contained $10 \mathrm{mmol} \mathrm{L}^{-1}$ insulin precursor, $200 \mu \mathrm{mol} \mathrm{L} \mathrm{L}^{-1}$ trypsin, $0.8 \mathrm{~mol} \mathrm{~L}^{-1} \mathrm{H}$ -
Thr(tBu)-OtBu, 7 mmol L-1 $\mathrm{CaCl}_{2}, 50 \%$ dimethylformamide/ethanol $1: 1(\mathrm{v} / \mathrm{v})$ and $26 \%$ water with the $\mathrm{pH}$ adjusted to $\mathrm{pH} 6.0$ with acetic acid. The reaction was carried out at $12^{\circ} \mathrm{C}$ for $24 \mathrm{hrs}$. The reaction mixture was subjected to semi-preparative gradient chromatography for purification of pre-insulin using a Resource RPC column (GE Healthcare). The bound pre-insulin was eluted by a gradient formed by mixing solutions A $\left(0.2 \mathrm{~mol} \mathrm{~L}^{-1}\right.$ ammonium sulphate buffer, $\mathrm{pH} 2.0)$ and $\mathrm{B}\left(0.1 \mathrm{~mol} \mathrm{~L}^{-1}\right.$ ammonium sulphate buffer with $40 \%(\mathrm{v} / \mathrm{v})$ acetonitrile) as follows: 0 - 45\% B (16.6 column volumes, CV), 45\% B (16.6 CV), 45 - 75\% B (16.6 CV), 75\% B (2.7 CV), 75 $100 \%$ B (3 CV). The purified pre-insulin was desalted by cation exchange chromatography (HiTrap SP HP column, GE Healthcare, elution with $100 \mathrm{mmol} \mathrm{L}-1 \mathrm{NH}_{4} \mathrm{HCO}_{3}, \mathrm{pH}$ 9) and lyophilized prior to further processing.

Pre-insulin was transformed to human insulin by removal of the tertiary-butyl groups of threonine in position B30 by acidolysis using trifluoroacetic acid $(19 \mu \mathrm{L}$ TFA per mg pre-insulin). To protect the polypeptide from degradation and desamidation, $0.05 \mathrm{mg}$ each of L-tryptophan and L-glutamine per mg pre-insulin were included as scavengers in the reaction mixture which also contained $2.5 \%$ water.

Final purification of human insulin was carried out by semi-preparative gradient chromatography (Resource RPC column, GE Healthcare). The deprotection reaction mixture was subjected to gradient chromatography by mixing solutions A [90\% ammonium acetate buffer (1 mol L-1, pH 7.0) and 10\% acetonitrile] and B [50\% ammonium acetate buffer $\left(1 \mathrm{~mol} \mathrm{~L}^{-1}, \mathrm{pH} 7.0\right)$ and $50 \%$ acetonitrile] as follows: 0 - 35\% B (1 CV), 35\% B (26.6 CV), 35 - $50 \%$ B (6 CV), 50\% B (6 CV), 50 - 100\% B (4 CV). The eluted recombinant human insulin was desalted and lyophilized as described above for long term storage.

\section{Mass spectrometry}

Electrospray mass spectrometry (ESI-MS) was performed with API 150EX, PE SCIEX instrument (Applied Biosystems). Samples eluted from Resource RPC columns were desalted (HiTrap SP HP column, GE Healthcare) and lyophilized. Lyophilized samples were reconstituted in $0.1 \%$ TFA and $80 \%$ acetonitrile in MilliQ water and analyzed by direct infusion $\left(5 \mu \mathrm{L} \mathrm{min}{ }^{-1}\right)$ in the interval of $600-2500$ $\mathrm{m} / \mathrm{z}$. Spectra were acquired using LC2Tune 1.4 Software and the molecular mass was obtained by automatic deconvolution using the Biomultiview software.

\footnotetext{
Competing interests

The authors declare that they have no competing interests.
}

\section{Authors' contributions}

CG and AA carried out the cultivations. CG and SP carried out the purification. CG performed the IP determinations. TG implemented the methanol controller. NS and ST were responsible for the design of the IP clone, purification of IP and transpeptidation. DC and NK were responsible for the generation of the Pichia pastoris clone. SS and NK prepared the initial draft. UR conceived and 
directed the cultivation experiments and prepared the final manuscript. All authors read and approved the final manuscript.

\section{Acknowledgements}

This work was supported by institutional core funds of ICGEB and Helmholtz Centre for Infection Research and an Indo-German collaborative grant from the Department of Biotechnology, Govt. of India. Ahmad Adnan wishes to express his gratitude to the Higher Education Commission (HEC) of Pakistan for a post-doctoral fellowship. The authors thank Francisco E. Baralle for his support throughout and Guarnaccia Corrado and Zahariev Sotir for mass spectrometry analysis. They also acknowledge the valuable assistance provided by Reinhard Sterlinski, Burkhard Ebert, Maren Michel, Daniela Gebauer, and Poornima Tyagi during different phases of this study.

\section{Author Details}

${ }^{1}$ Helmholtz Centre for Infection Research, Braunschweig, Germany, IInternational Centre for Genetic Engineering \& Biotechnology, New Delhi, India, ${ }^{3}$ nternational Centre for Genetic Engineering \& Biotechnology, Trieste, Italy, ${ }^{4}$ Department of Chemistry, Government College University Lahore, Pakistan and 5Fraunhofer ITEM, Hannover/Braunschweig, Germany

Received: 27 January 2010 Accepted: 12 May 2010

Published: 12 May 2010

\section{References}

1. Document-WHO/NCD/NCS/99.2: Definition, diagnosis and classification of diabetes mellitus and its complications World Health Organization 1999 [http://whqlibdoc.who.int/hq/1999/ WHO NCD NCS 99.2.pdf]. Accessed on 02.09.2009

2. Diabetes Fact sheet No 312 World Health Organization 2008 [http:// www.who.int/mediacentre/factsheets/fs312/en/

3. Wild S, Roglic G, Green A, Sicree R, King H: Global prevalence of diabetes: estimates for the year 2000 and projections for 2030. Diabetes Care 2004, 27:1047-1053.

4. Vajo Z, Fawcett J, Duckworth WC: Recombinant DNA technology in the treatment of diabetes: insulin analogs. Endocr Rev 2001, 22:706-717.

5. Ahmad B: Pharmacology of insulin. Br J Diabetes Vasc Dis 2004, 4:10-14.

6. Walsh G: Therapeutic insulins and their large-scale manufacture. Appl Microbiol Biotechnol 2005, 67:151-159.

7. Ferrer-Miralles N, Domingo-Espin J, Corchero JL, Vazquez E, Villaverde A Microbial factories for recombinant pharmaceuticals. Microb Cell Fact 2009, 8:17.

8. Goeddel DV, Kleid DG, Bolivar F, Heyneker HL, Yansura DG, Crea R, Hirose T, Kraszewski A, Itakura K, Riggs AD: Expression in Escherichia coli of chemically synthesized genes for human insulin. Proc Natl Acad Sci USA 1979, 76:106-110.

9. Schmidt M, Babu KR, Khanna N, Marten S, Rinas U: Temperature-induced production of recombinant human insulin in high-cell density cultures of recombinant Escherichia coli. J Biotechnol 1999, 68:71-83.

10. Nilsson J, Jonasson P, Samuelsson E, StåhI S, Uhlén M: Integrated production of human insulin and its C-peptide. J Biotechnol 1996, 48:241-250.

11. Thim L, Hansen MT, Norris K, Hoegh I, Boel E, Forstrom J, Ammerer G, Fiil NP: Secretion and processing of insulin precursors in yeast. Proc Natl Acad Sci USA 1986, 83:6766-6770.

12. Markussen J, Damgaard U, Diers I, Fiil N, Hansen MT, Larsen P, Norris F, Norris K, Schou O, Snel L, Thim L, Voigt HO: Biosynthesis of human insulin in yeast via single chain precursors. Diabetologia 1986, 29:568A-569A.

13. Kjeldsen T: Yeast secretory expression of insulin precursors. Appl Microbiol Biotechnol 2000, 54:277-286.

14. Hollenberg CP, Gellissen G: Production of recombinant proteins by methylotrophic yeasts. Curr Opin Biotechnol 1997, 8:554-560.

15. Gellissen $G$, Hollenberg CP: Application of yeasts in gene expression studies: a comparison of Saccharomyces cerevisiae, Hansenula polymorpha and Kluyveromyces lactis - a review. Gene 1997, 190:87-97.

16. Romanos M: Advances in the use of Pichia pastoris for high-level gene expression. Curr Opin Biotechnol 1995, 6:527-533.

17. Weydemann U, Keup P, Piontek M, Strasser AW, Schweden J, Gellissen G, Janowicz ZA: High-level secretion of hirudin by Hansenula polymorphaauthentic processing of three different preprohirudins. App/Microbiol Biotechnol 1995, 44:377-385.
18. Porro D, Sauer M, Branduardi P, Mattanovich D: Recombinant protein production in yeasts. Mol Biotechnol 2005, 31:245-259.

19. Cereghino GP, Cereghino JL, Ilgen C, Cregg JM: Production of recombinant proteins in fermenter cultures of the yeast Pichia pastoris. Curr Opin Biotechnol 2002, 13:329-332.

20. Li P, Anumanthan A, Gao XG, llangovan K, Suzara W, Duzgunes N, Renugopalakrishnan $\mathrm{V}$ : Expression of recombinant proteins in Pichia pastoris. Appl Biochem Biotechnol 2007, 142:105-124

21. Macauley-Patrick S, Fazenda ML, McNeil B, Harvey LM: Heterologous protein production using the Pichia pastoris expression system. Yeast 2005, 22:249-270

22. Kjeldsen T, Pettersson AF, Hach M: Secretory expression and characterization of insulin in Pichia pastoris. Biotechnol App/Biochem 1999, 29:79-86.

23. Mansur M, Cabello C, Hernandez L, Pais J, Varas L, Valdes J, Terrero Y, Hidalgo A, Plana L, Besada V, Garcia L, Lamazares E, Castellanos L, Martinez $E$ : Multiple gene copy number enhances insulin precursor secretion in the yeast Pichia pastoris. Biotechnol Lett 2005, 27:339-345.

24. Pais-Chanfrau JM, Garcia Y, Licor L, Besada V, Castellanos-Serra L, Cabello Cl, Hernandez L, Mansur M, Plana L, Hidalgo A, Tambara Y, del CA-P, del TY, Valdes J, Martinez E: Improving the expression of mini-proinsulin in Pichia pastoris. Biotechnol Lett 2004, 26:1269-1272.

25. Pais JM, Varas L, Valdes J, Cabello C, Rodriguez L, Mansur M: Modeling of mini-proinsulin production in Pichia pastoris using the AOX promoter. Biotechnol Lett 2003, 25:251-255.

26. Wang $Y$, Liang Z-H, Zhang Y-S, Yao S-Y, Xu Y-G, Tang Y-H, Zhu S-Q, Cui D-F, Feng $Y$-M: Human insulin from a precursor overexpressed in the methylotrophic yeast Pichia pastoris and a simple procedure for purifying the expression product. Biotechnol Bioeng 2001, 73:74-79.

27. Xie T, Liu Q, Xie F, Liu H, Zhang Y: Secretory expression of insulin precursor in Pichia pastoris and simple procedure for producing recombinant human insulin. Prep Biochem Biotechnol 2008, 38:308-317.

28. Zhu T, Guo M, Tang Z, Zhang M, Zhuang Y, Chu J, Zhang S: Efficient generation of multi-copy strains for optimizing secretory expression of porcine insulin precursor in yeast Pichia pastoris. J App/ Microbio/ 2009, 107:954-963.

29. Ding J-G, Fei J, Cui D-F, Zhang Y-S: Expression of monomeric insulin precursor in Pichia pastoris and its conversion into monomeric B27 Lys destripeptide insulin by tryptic hydrolysis. Acta Biochim Biophys Sin (Shanghai) 2005, 37:234-240.

30. Gao J-K, Cai S-X, Fan K, Feng Q, Chen H-R, Zhang Y, Hu W, Yang Y-B: Expression of human mini-proinsulin DesB ${ }^{30}$ in Pichia pastoris and procedure for purifying the expression product. Prog Biochem Biophys 2009, 35:63-68.

31. Markussen J, Fiil N, Hansen MT, Norris K, Ammerer G, Thim L, Voigt HO: DNA-sequence encoding biosynthetic insulin precursors and process for preparing the insulin precursors and human insulin. US Patent 4,916,2121990.

32. Kjeldsen T, Brandt J, Andersen AS, Egel-Mitani M, Hach M, Pettersson AF, Vad K: A removable spacer peptide in an alpha-factor-leader/insulin precursor fusion protein improves processing and concomitant yield of the insulin precursor in Saccharomyces cerevisiae. Gene 1996, 170:107-112.

33. Morihara K, Ueno Y, Sakina K: Influence of temperature on the enzymic semisynthesis of human insulin by coupling and transpeptidation method. Biochem J 1986, 240:803-810.

34. Markussen J: Process for preparing esters of human insulin. US Patent 4,489,159 1984

35. Gurramkonda C, Adnan A, Gäbel T, Lünsdorf H, Ross A, Nemani SK, Swaminathan S, Khanna N, Rinas U: Simple high-cell density fed-batch technique for high-level recombinant protein production with Pichia pastoris: Application to intracellular production of Hepatitis B surface antigen. Microb Cell Fact 2009, 8:13.

36. Ramesh $\mathrm{V}$, Bradbury $\mathrm{JH}:{ }^{1} \mathrm{H}$ NMR studies of insulin: histidine residues, metal binding, and dissociation in alkaline solution. Arch Biochem Biophys 1987, 258:112-122.

37. Kaarsholm NC, Ko HC, Dunn MF: Comparison of solution structural flexibility and zinc binding domains for insulin, proinsulin, and miniproinsulin. Biochemistry 1989, 28:4427-4435.

38. Grant PT, Coombs TL, Frank BH: Differences in the nature of the interaction of insulin and proinsulin with zinc. Biochem J 1972, 126:433-440. 
39. Insulin, human 01/2005:0838 EUROPEAN PHARMACOPOEIA 5.02005 [http://www.uspbpep.com/ep50/Insulin,\%20human.pdf].

40. Gasser B, Saloheimo M, Rinas U, Dragosits M, Rodríguez-Carmora E, Baumann K, Giuliani M, Parrilli E, Branduardi P, Lang C, Porro D, Ferrer P, Tutino ML, Mattanovich D, Villaverde A: Conformational stress in microbial cells producing recombinant proteins: a host comparative overview. Microb Cell Fact 2008, 7:11.

41. Vassileva A, Chugh DA, Swaminathan S, Khanna N: Expression of hepatitis B surface antigen in the methylotrophic yeast Pichia pastoris using the GAP promoter. J Biotechnol 2001, 88:21-35.

42. Schägger $H$, von Jagow $\mathrm{G}$ : Tricine-sodium dodecyl sulfatepolyacrylamide gel electrophoresis for the separation of proteins in the range from 1 to $100 \mathrm{kDa}$. Anal Biochem 1987, 166:368-379.

43. Brixius P, Mollerup I, Jensen OE, Halfar M, Thommes J, Kula MR: Expanded bed adsorption as a primary recovery step for the isolation of the insulin precursor MI3 process development and scale up. Biotechnol Bioeng 2006, 93:14-20.

doi: 10.1186/1475-2859-9-31

Cite this article as: Gurramkonda et al., Application of simple fed-batch technique to high-level secretory production of insulin precursor using Pichia pastoris with subsequent purification and conversion to human insulin Microbial Cell Factories 2010, 9:31

Submit your next manuscript to BioMed Central and take full advantage of:

- Convenient online submission

- Thorough peer review

- No space constraints or color figure charges

- Immediate publication on acceptance

- Inclusion in PubMed, CAS, Scopus and Google Scholar

- Research which is freely available for redistribution

Submit your manuscript at www.biomedcentral.com/submit
C) Biomed Central 